Original Research Article

\title{
Analysis of gastrointestinal drugs in patients admitted in CCU and ICCU of a tertiary care hospital in Goa, India
}

\author{
Shantadurga S. Kerkar*, Padma N. Bhandare
}

Department of Pharmacology,

Goa Medical College,

Bambolim Goa, India

Received: 11 February 2019

Accepted: 14 March 2019

\section{*Correspondence to:}

Dr. Shantadurga S. Kerkar,

Email: kerkarshantadurga@ gmail.com

Copyright: (C) the author(s), publisher and licensee Medip Academy. This is an openaccess article distributed under the terms of the Creative Commons Attribution NonCommercial License, which permits unrestricted noncommercial use, distribution, and reproduction in any medium, provided the original work is properly cited.

\begin{abstract}
Background: Gastrointestinal (GI) diseases are a common problem worldwide. They are frequently encountered in non-critical as well as in critically ill hospitalized patients.

Methods: This was a prospective and observational study conducted on patients admitted in CCU and ICCU of Goa Medical College and Hospital. Data was collected from the patients' case records and was analysed referring to WHO prescribing indicators. Data was represented as Mean $\pm \mathrm{SD}$, number and frequency.

Results: A total of 2250 drugs were prescribed, out of which $376(16.71 \%)$ were gastrointestinal drugs. Most common route of administration was oral 323 $(85.90 \%)$. Prescription patterns of GI drugs were: $275(73.14 \%)$ from National List of Essential Medicines, $20(5.31 \%)$ as fixed dose combinations and $4(1.06 \%)$ by generic names. Pantoprazole $183(48.67 \%)$ was the most frequently prescribed drug for peptic ulcer in present study.

Conclusions: From the findings of this study we noted that among the GI drugs used, those for peptic ulcer were the most commonly prescribed. Also majority were from the essential drug list. But prescribing by generic names was low. Review of drug utilization trends is a necessary aid to formulate and modify existing protocols and guidelines to improve treatment outcomes in a given setting.
\end{abstract}

Keywords: Critically-ill patients, Gastrointestinal ailments, Medicines, PPIs

\section{INTRODUCTION}

Gastrointestinal (GI) diseases are a problem worldwide and more so in the developing countries. Conditions included in these diseases are vomiting, diarrhoea, dysentery, cholera, viral hepatitis, gastro-oesophageal reflux disease (GERD), non- alcoholic fatty liver diseases, colorectal cancer etc, however a change in pattern of these diseases is seen over the time. Improper sanitation, contaminated food and drinking water, poverty, low literacy rate, rapid modernization and lifestyle changes could be some of the causative factors. ${ }^{1-3}$
GI ailments are also encountered in the hospitalized patients and more so among the patients admitted in the emergency departments (CCU and ICCU). Reasons additionally could be due to impaired GI motility, impaired mucosal barrier, hospital acquired infections, adverse reactions to concomitant drugs used, which can further lead to complications and morbidity in these patients. $^{4}$

Though the treatment of GI diseases over the years has not changed much, to provide appropriate individualized treatment to such patients poses tough challenge to a 
practising physician and at times may also compel the usage of multiple drugs. ${ }^{4}$

For optimum treatment outcomes it becomes important to ensure that medications used are safe, efficacious and prescribed rationally. Irrational and inappropriate prescriptions are a common problem encountered nowadays, leading to various health hazards, adverse reactions and drug interactions. ${ }^{5}$

A prescription based survey can be one of the effective aid in overcoming the above problems and also improve quality of drug therapy. ${ }^{5}$ Evaluation of drug usage patterns helps to monitor and pinpoint any deficiencies if present, suggest possible modifications and thus provide safe, effective and economical therapy to patients. ${ }^{6}$ WHO has outlined various criteria to monitor and supervise treatment practices and drug use behaviours. ${ }^{7}$

Review of various data shows that studies concerning drug usage in gastrointestinal diseases are few and so conduction of these studies are important. ${ }^{4}$ Hence we planned this study with an effort to analyse the prescribing trends of gastrointestinal drugs used in patients admitted in CCU and ICCU of a tertiary care hospital.

\section{METHODS}

This was a prospective, observational study conducted on patients admitted in CCU and ICCU of Goa Medical College \& Hospital. After approval from the Institutional Ethics Committee, informed consent was obtained from the patients or their kin. Medical records of 250 patients admitted between Jan 2018 to July 2018 were analyzed for demographic variables, details of drugs: name of the drug, dosage form, prescribing frequency, duration of treatment, and brand/ generic name.

\section{The collected data was used to evaluate the following WHO prescribing indicators ${ }^{7}$}

- Average number of drugs prescribed per patient encounter

- Percentage of drugs prescribed by generic names

- Percentage of encounters of injectable drugs prescribed

- Percentage of drugs prescribed from list of essential medicines.

\section{Inclusion criteria}

All patients admitted in CCU and ICCU for $>24 \mathrm{hrs}$ and were prescribed at least one gastrointestinal drug and also willing to give consent for the study, were included in the study

\section{Exclusion criteria}

- Patients / kin not willing to participate in the study.

- Patients discharged against medical advice.

\section{Statistical analysis}

Results were expressed as Mean \pm SD for quantitative data and for qualitative data they were expressed as number and frequency.

\section{RESULTS}

The present study consisted of 250 patients, males 135 (54\%) and females being 115 (46\%) (Figure 1).

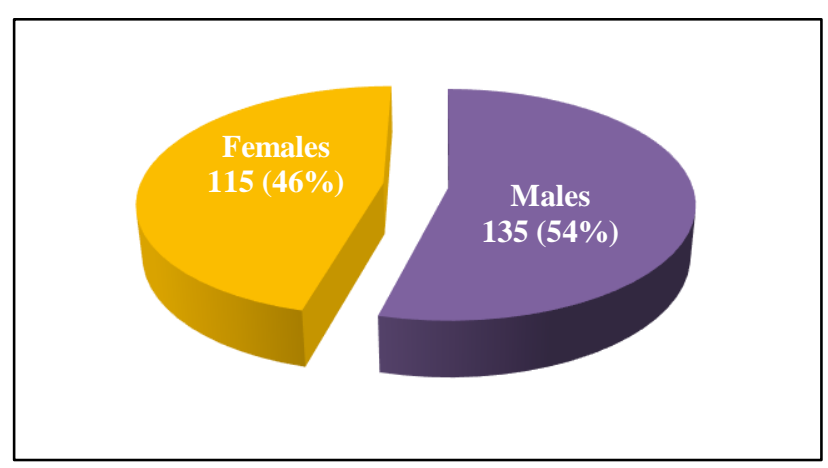

Figure1: Gender distribution.

Total $81(32.4 \%)$ belonged to the age group of 51-60 yrs, which was maximum, followed by 60 (24\%) and 41 (16.4\%) in the age groups of 61-70 yrs and 41-50 yrs respectively. The age wise distribution of patients is depicted in the Table 1. Average duration of stay in CCU /ICCU was $2.71 \pm 1.8$ days.

Table 1: Age wise distribution.

\begin{tabular}{|lll|}
\hline Age in years & No of patients & $\%$ \\
\hline$<20$ & 3 & 1.2 \\
\hline $21-30$ & 7 & 2.8 \\
\hline $31-40$ & 18 & 7.2 \\
\hline $41-50$ & 41 & 16.4 \\
\hline $51-60$ & 81 & 32.4 \\
\hline $61-70$ & 60 & 24 \\
\hline $71-80$ & 36 & 14.4 \\
\hline $81-90$ & 4 & 1.6 \\
\hline
\end{tabular}

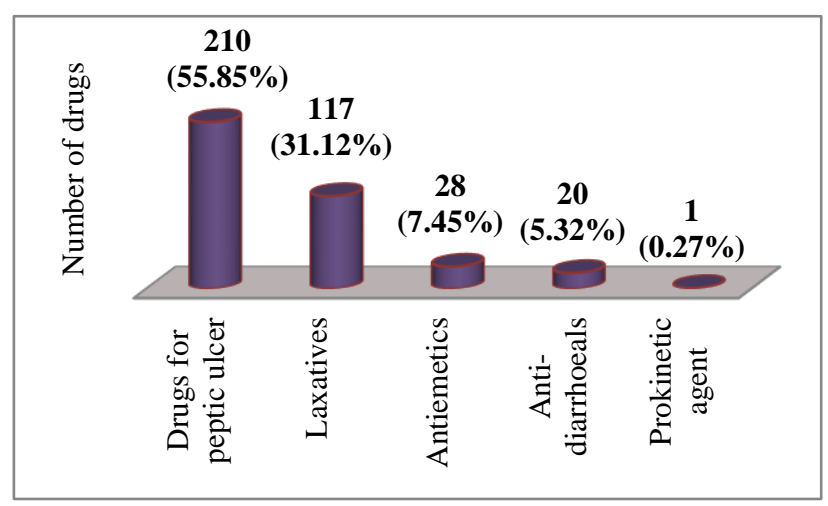

Figure 2: Pharmacological classes of gastrointestinal drugs. 
The total number of drugs prescribed to this study patients were 2250. Out of which 376 (16.71\%) were gastrointestinal drugs with an average drug per patient being $1.34 \pm 1.1$.

It was observed that most of the prescriptions were for peptic ulcer $210(55.85 \%)$ and laxatives $117(31.12 \%)$ followed them. Figure 2 depicts pharmacological classes of GI drugs.

Pantoprazole $183(48.67 \%)$ was the most frequently prescribed gastrointestinal drug followed by lactulose 48 $(12.77 \%)$ and ondansetron $28(7.45 \%)$. Figure 3 depicts gastrointestinal drugs prescribed.

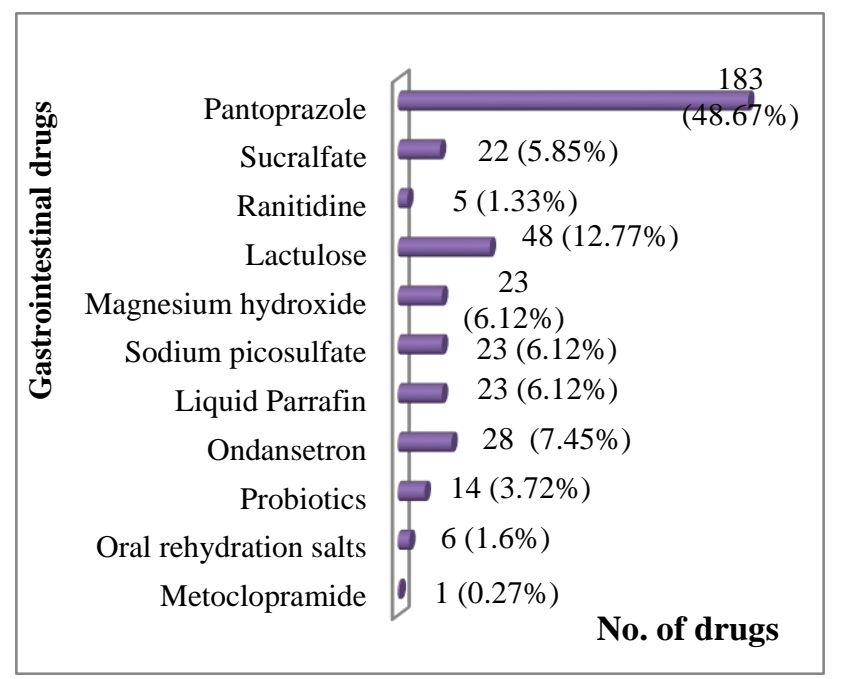

Figure 3: Gastrointestinal drugs prescribed.

Total $4(1.06 \%)$ drugs were prescribed by generic names. Oral administration was of $323(85.90 \%)$ drugs while that of injectable was $53(14.09 \%)$. Drugs administered from national list of essential medicines (NLEM) were 275 (73.14\%) (Table 2). Fixed dose combination prescriptions for GI drugs were found to be $20(5.31 \%)$.

Table 2: Analysis of parameters referring to the WHO prescribing indicators.

\begin{tabular}{|lll|}
\hline WHO prescribing indicators & No. & Percentage \\
\hline $\begin{array}{l}\text { Average no of GI drugs } \\
\text { prescribed per patient }\end{array}$ & $1.34 \pm 1.1$ & - \\
\hline $\begin{array}{l}\text { Percentage of GI drugs } \\
\text { prescribed by generic names }\end{array}$ & 4 & $1.06 \%$ \\
\hline $\begin{array}{l}\text { Percentage encounters with an } \\
\text { injection prescribed }\end{array}$ & 53 & $14.09 \%$ \\
\hline $\begin{array}{l}\text { Percentage of drugs prescribed } \\
\text { from list of essential medicines } \\
\text { (NLEM) }\end{array}$ & 275 & $73.14 \%$ \\
\hline
\end{tabular}

\section{DISCUSSION}

Emergency medicine department of any tertiary care hospital is often faced with large inflow of patients with critical illnesses at times needing aggressive treatment modalities. Medicines form an integral part of health care in these patients. For better treatment outcomes drugs administered should be safe, efficacious, cost-effective and appropriately prescribed. Therefore, periodic prescription audit becomes necessary to ensure rationality of a treatment. $^{9,10}$

In this study in emergency department of CCU and ICCU $135(54 \%)$ were males and $115(46 \%)$ were females, a similar pattern of gender distribution was noted in a study conducted by Kaur S et al, (males $66.9 \%$ and females $33 \%) .{ }^{10}$ Among the patients admitted, maximum were 81 $(32.4 \%)$ in the age group of 51- $60 \mathrm{yrs}$. This finding was in accordance with a study carried out by Gupta R et al, 58 $(39.72 \%) .{ }^{11}$ Older age group is challenged with various age-related health problems and co-morbidities. Debilitating effects of multiple, acute and chronic ailments may at times need hospitalization and long-term care. ${ }^{12}$ The average duration of stay was $2.71 \pm 1.8$ days, while Kaur S. et al, reported a duration of $2.23 \pm 1.3$ days. ${ }^{10}$ This duration is required for effective management of critical ailments.

In present study out of the total of 2250 drugs administered the prescribing frequency of GI drugs was 376 (16.71\%), which was comparatively lower than those noted by Aljarari NMH et al, 137 (32.5\%) and Mamatha V et al, 197 $(19.4 \%){ }^{5,13}$ With urbanization, modernization and lifestyle changes there have been increased incidences and changes in the patterns of gastrointestinal ailments like GERD, peptic ulcers, GI cancers, non fatty liver diseases etc noted. ${ }^{3}$ Critically ill patients are at times more vulnerable to occurrence of stress ulcers, emesis, constipation which can occur not only in addition to the ailments they are suffering but also as a result of adverse effects of concomitant drugs prescribed during the hospital stay. Hence GI drugs may be prescribed therapeutically as well as prophyllactically. ${ }^{4,14}$

The average number of drugs prescribed per patient was $1.34 \pm 1.1$ which was comparable to a study by Aljarari NMH et al, (1-2 drugs). ${ }^{5}$ This low average is an appreciable finding, as prescriptions with multiple drugs may not only cause serious adverse events and drug interactions but also can cause economic burden on patients leading to non compliance and inadequate treatment outcomes. ${ }^{15}$ Thus practice of polypharmacy needs to be avoided wherever possible.

In present study noted that only $4(1.06 \%)$ GI drugs were prescribed by generic names which correlated with the results of a study by Aljarari NMH et al, where all drugs were prescribed by brand names. ${ }^{5}$ One of the reasons for low number of prescriptions by generic names could be because prescribing a usual brand may increase patient compliance as they develop faith in the brands they use. Also, a practicing physician may consider prescribing a particular brand because of their own earlier experiences, better therapeutic outcomes, efficacy and safety profiles. ${ }^{16}$ Prescriptions with generic names may give liberty to 
pharmacists to dispense drugs of their choice which may cause complications like adverse reactions and drug interactions. ${ }^{17}$ Sometimes the excipients can also give rise to drug interactions.

The most common route of administration of GI drugs was oral $323(85.90 \%)$ drugs. Percentage encounters with an injection prescribed were $53(14.09 \%)$. Prescriptions with higher parenteral formulations though less cost effective but may be necessary at times due to faster onset of action of drugs and relief of symptoms. ${ }^{14}$

Total $275(73.14 \%)$ of the GI drugs prescribed in this study were from National List of Essential Medicines and is in comparison with a study by John L et al, 68\%., ${ }^{4,8}$ This practice of prescribing drugs from the essential drugs list with high frequency is definitely an adorable one, especially as Goa Medical College and Hospital is the only tertiary care hospital which caters the entire state of Goa. $20(5.31 \%)$ of GI drugs prescribed as FDCs, FDCs improve compliance of patients by decreasing the number of pills. ${ }^{18}$

Among the GI drugs, most frequently prescribed were those for peptic ulcer $210(55.85 \%)$ in comparison to that prescribed in a study by Mamatha $\mathrm{V}$ et al. noted the same as $197(19.4 \%){ }^{13}$ Pantoprazole $183(48.67 \%)$ was the most frequently prescribed drug for peptic ulcer in present study followed by sucralfate $22(5.85 \%)$ and ranitidine 5 $(1.33 \%)$.

Studies by Ramesh L et al, 207 (87\%), John L et al, 607 (86\%), Meena VK et al, $148(74 \%)$ noted a higher prescribing frequency of pantoprazole while study by Kaur S. et al, $646(41.8 \%)$ showed a lower when compared to our study. ${ }^{4,6,10,19}$ Critically ill patients requiring intensive care set ups are often more prone to stress and so proton pump inhibitors are safe and efficacious for elevating gastric $\mathrm{pH}$ in these patients. They act by causing long lasting acid suppression by inactivating $\mathrm{H}^{+} \mathrm{K}^{+}$ATPase and thus are of choice because of once daily dosing schedule which improves patient compliance. ${ }^{13,14}$

Lactulose 48 (12.77\%) was the most commonly prescribed laxative in this study. This prescribing frequency is comparable to findings documented by John L et al, 82 $(11.6 \%)$ but lower than that noted by Arathy R et al, 135 $(22.5 \%) .^{4,20}$ Lactulose stimulates colonic propulsive motility by osmosis into the lumen and also approved to treat hepatic encephalopathy in patients with severe liver disease. $^{14}$ Magnesium hydroxide 23 (6.12\%), sodium picosulfate $23(6.12 \%)$ and liquid paraffin $23(6.12 \%)$ were the other laxatives prescribed in present study.

Ondansetron was the most commonly prescribed antiemetic $28(7.45 \%)$, its prescribing frequency noted by John L et al, was 105 (14.9\%) higher than that in present study. ${ }^{4}$ Ondansetron is a serotonergic receptor antagonist approved for conditions like chemotherapy or radiotherapy induced vomiting and post-operative nausea vomiting. Studies by Patka et al, suggested ondansetron to be equally effective as prochlorperazine at treating vomiting in the emergency department while Braude et al, reported that ondansetron and promethazine have similar efficacy in reducing nausea among adults in emergency department $^{.21,22}$

Probiotics and oral rehydration salts were the antidiarrhoeals prescribed in a frequency of $20(5.32 \%)$ which was higher than Ramesh L et al, 30 (2.65\%) but lower than Aljarari NMH et al, $34(8.1 \%)^{5,6}$

Table 3: Comparison of results of present study with similar studies.

\begin{tabular}{|c|c|c|}
\hline Parameters & Present study & Other studies \\
\hline Gender distribution & $\begin{array}{l}\text { Males } 135(54 \%) \\
\text { Females } 115(46 \%)\end{array}$ & Kaur et al ${ }^{10}:$ M- $66.9 \%$, F- $33 \%$ \\
\hline Age distribution (51-60 yrs) & $81(32.4 \%)$ & Gupta R. et $\mathrm{al}^{11}: 58(39.72 \%)$. \\
\hline Average duration of stay & $2.71 \pm 1.8$ days & Kaur S. et al ${ }^{10}: 2.23 \pm 1.3$ days \\
\hline Prescribing frequency of GI drugs & $376(16.71 \%)$ & Mamatha $\mathrm{V}$ et al ${ }^{13}: 197(19.4 \%)$ \\
\hline Average number of GI drugs prescribed per patient & $1.34 \pm 1.1$ & Aljarari NMH et $\mathrm{al}^{5}: 1-2$ drugs \\
\hline GI drugs prescribed by generic names & $4(1.06 \%)$ & $\begin{array}{l}\text { Aljarari NMH et } \mathrm{al}^{5} \text { : all drugs were } \\
\text { prescribed by brand names }\end{array}$ \\
\hline GI drugs were prescribed from NLEM & $275(73.14 \%)$ & John L et $\mathrm{al}^{4}: 68 \%$ \\
\hline \multirow{3}{*}{ Prescribing frequency of pantoprazole } & \multirow{3}{*}{$183(48.67 \%)$} & John L et al ${ }^{4}: 607(86 \%)$ \\
\hline & & Meena VK et al ${ }^{19}: 646(41.8 \%)$ \\
\hline & & Ramesh L et al ${ }^{6}: 207(87 \%)$ \\
\hline
\end{tabular}

A special mention about probiotics $14(3.72 \%)$ that were prescribed in patients with acute gastroenteritis. A few of clinical studies have documented that probiotics as an adjunct to rehydration therapy shortens the duration of diarrhea. ${ }^{23}$ Table 3 compares the findings of our study with similar other studies. 
The limitations of this study were that it was conducted in a single centre; greater number of comparative studies should be conducted in multiple centres. Sample size of the present study was 250 patients and was conducted for duration of 7 months. Studies with larger sample size conducted for a longer duration are needed.

\section{CONCLUSION}

In this study average number of gastrointestinal drugs per patient was low and a large amount of drugs were from essential drug list which was a good practice, however, only few prescriptions of drugs with generic names were encountered. Among the various classes of gastrointestinal drugs, drugs for peptic ulcer were the most commonly prescribed drugs among the critically ill patients.

The present study highlights that treating physicians must be sensitized and encouraged to prescribe drugs by generic names, the patients too should be sensitized and encouraged to take medicines by generic names. And thus, adhere to national essential medicine list a forward step to promoting rational pharmacotherapy. Periodic studies to evaluate drug utilization trends can aid to formulate and modify protocols and guidelines to improve treatment outcomes in any hospital setting.

Rapid modernization of techniques like endoscopies, different types of scans, MRIs etc have led to better and early diagnosis of GI diseases which will also need the use of drugs for their management. So, it is necessity of time to also keep an audit on drug usage pattern.

\section{ACKNOWLEDGEMENTS}

Authors are thankful to the staff of CCU and ICCU of Goa Medical College and Hospital.

Funding: No funding sources Conflict of interest: None declared

Ethical approval: The study was approved by the Institutional Ethics Committee

\section{REFERENCES}

1. Dhawan P, Desai H. Prevention of gastrointestinal diseases. Natl Med J India. 1996;9(2):72-75.

2. Williams J, Roberts S, Ali F, Cheung W, Cohen D, Demery $\mathrm{G}$ et al. Gastroenterology services in the UK. The burden of disease, and the organisation and delivery of services for gastrointestinal and liver disorders: a review of the evidence. Gut. 2007;56(suppl_1):1-113.

3. Goh KL. Changing trends in gastrointestinal disease in the Asia-Pacific region. Jo Dig Dis. 2007 Nov;8(4):179-85.

4. John L, Padmini D, Shoba G. Utilization Profile of Gastrointestinal Medications among the Critically Ill Patients of A Tertiary Care Hospital. Jordan J Pharmaceuti Sci. 2013;6(3):299-306.
5. Aljarari NMH, Sharif SI, Jaber AK, Garini AS, Awad AS, Hamed FA. Prescribing patterns of gastrointestinal drugs in private clinics in BenghaziLibya. Int J Basic Clin Pharmacol. 2017;6:113-6.

6. Ramesh L. Study of drug prescriptions in medical inpatients in a teaching hospital. Int $\mathrm{J}$ Basic Clin Pharmacol. 2016;5:2630-3.

7. Introduction to Drug Utilization Research: Chapter 3: Sources of data on drug utilization: 3.4 Practice setting data: 3.4.1 Prescribing data. Available at: http://apps.who.int/medicinedocs/en/d/Js4876e/4.4.1. html. Accessed 9 October 2018.

8. National List of Essential Medicines (NLEM) 2015 India. Available at: http://apps.who.int/medicinedocs/en/d/Js23088en/. Accessed 12 September 2018.

9. Neupane P, Giri P, Nagalatha D. A Study on Prescribing Pattern of Proton Pump Inhibitors at A Private Tertiary Care Hospital. Am J Pharm Health Res. 2016;4(4):54-68.

10. Kaur S, Rajagopalan S, Kaur N, Shafiq N, Bhalla A, Pandhi P, Malhotra S. Drug utilization study in medical emergency unit of a tertiary care hospital in North India. Emergency Med Int. 2014;2014.

11. Gupta R. Drug prescribing pattern in intensive care unit (ICU) in a tertiary care teaching hospital in Central India. Int J Pharm Bio Sci. 2015;6(3):325-9

12. Mafauzy M. The problems and challenges of the aging population of Malaysia. Malaysian J Med Sci. 2000 Jan;7(1):1.

13. Mamatha V, Parashivamurthy BM, Suneetha DK. Study of drug utilization pattern in emergency medicine ward at a tertiary care teaching hospital. Int J Basic Clin Pharmacol. 2017;6:868-73.

14. Brunton L, Knollmann B, Hilal-Dandan R. Goodman \& Gilman's the pharmacological basis of therapeutics. 13th ed. McGraw-Hill Education; 2017.

15. Rambhade S, Shrivastava A, Rambhade A, Chakarborty A, Patil U. A survey on polypharmacy and use of inappropriate medications. Toxicol Int. 2012;19(1):68.

16. Steinman M, Chren M, Landefeld C. What's in a Name? Use of Brand versus Generic Drug Names in United States Outpatient Practice. J General Internal Med. 2007;22(5):645-648.

17. Kumar R, Bajaj JK, Sood M, Grewal N, Jassal B. To study prescription behaviour of physician in regard to brand and generic name. Int J Basic Clin Pharmacol. 2016;5:1327-30.

18. Pan F, Chernew M, Fendrick A. Impact of Fixed-Dose Combination Drugs on Adherence to Prescription Medications. J General Internal Med. 2008;23(5):6114.

19. Meena VK, Atray M, Agrawal A. Evaluation of Drug Utilization Pattern In Indoor Patients Of Medicine Department At Tertiary Care Teaching Hospital In Southern Rajasthan. IJPSR. 2016 Sep 1;7(9):3835-40.

20. Arathy R, Chacko J, Pillai S, Bhanu A, Raphael R, Jalajakumari M. Drug utilisation in medical intensive care unit: a retrospective analysis from a tertiary care 
teaching hospital. Int $\mathrm{J}$ Basic Clin Pharmacol. 2016;5(4):1201-4.

21. Patka J, Wu DT, Abraham P, Sobel RM. Randomized controlled trial of ondansetron vs. prochlorperazine in adults in the emergency department. Western J Emergency Med. 2011 Feb;12(1):1.

22. Braude D, Crandall C. Ondansetron versus promethazine to treat acute undifferentiated nausea in the emergency department: a randomized, doubleblind, noninferiority trial. Academic Emergency Med. 2008 Mar;15(3):209-15.
23. Isolauri E. Probiotics for infectious diarrhoea. Gut. 2003 Mar 1;52(3):436-7.

Cite this article as: Kerkar SS, Bhandare PN. Analysis of gastrointestinal drugs in patients admitted in CCU and ICCU of a tertiary care hospital in Goa, India. Int J Basic Clin Pharmacol 2019;8:782-7. 